\title{
Exon1 and $-116 C / G$ Promoter Polymorphism on the X-Box DNA Binding Protein- 1 Gene is not Associated with Breast Cancer among Jordanian Women
}

\author{
Lulu H Alsheikh Hussein, Ahmad M Khalil*, Ahmad Y Alghadi, Abed Alkarem \\ Abu Alhaija
}

\begin{abstract}
Background: Human $X$-box binding protein $1(X B P 1)$, a critical gene in the endoplasmic reticulum stress response, is located on chromosome 22q12, which has been linked with the pathogenesis of many diseases, particularly cancers such as breast cancer (BC). Single nucleotide polymorphisms (SNPs) in the $X B P 1$ gene can alter structure and function of the gene. In this study, polymorphism in the promoter region and exon1 of the gene $X B P 1$ and its association with $\mathrm{BC}$ in Jordanian women was investigated. Methods: Polymorphism in the promoter and exon 1 of $X B P 1$ was analyzed in 100 subjects (controls: $\mathrm{n}=40$; $\mathrm{BC}$ patients $=60$ ). $-116 C / G$ SNP was genotyped by Polymerase Chain Reaction (PCR)-sequence specific primer technique. The odd ratios (ORs) at 95\% confidence intervals (CIs) were computed to assess the strength of this association. Results: The three genotypes of the SNP (GG, GC, CC) and their allelic frequencies have nonsignificant differences between patients and control group. It was noticed that the frequencies of the mutant allele $(\mathrm{G})$ were $(75.8 \%$ versus $24.2 \%)$ ) in the patients and control groups, respectively, while those of the normal allele $(\mathrm{C})$ were $(67.5 \%$ versus $32.5 \%) . X B P 1(-116 \mathrm{G} \rightarrow \mathrm{C}) \mathrm{G}$ allele did not show significant association with $\mathrm{BC}$ risk (confidence interval $=0.3534-1.2395$, odds ratio $=0.6619, \mathrm{P}=0.197$ ). Moreover, there were no significant mutations in the $X B P 1$ exon1 neither in $\mathrm{BC}$ subjects nor control subjects. Conclusions: This is the first study to evaluate the effect of polymorphism in the promoter and exon1 of XBP1 gene in the pathogenesis of $\mathrm{BC}$ in Jordanian women. The results do not support a role for polymorphism in development of $\mathrm{BC}$ and further studies with a larger sample size and detailed data should be performed in other populations.
\end{abstract}

Keywords: $-116 C / G$ polymorphism- breast cancer- SNPs- $X B P$ lgene

Asian Pac J Cancer Prev, 20 (9), 2739-2743

\section{Introduction}

Breast cancer $(\mathrm{BC})$ is considered to be the most common carcinoma and the second leading cause of cancer-related death in women throughout the world (Siegel et al., 2018). BC is a public health problem in most countries as stated by the World Health Organization (WHO, 2008). Official Jordanian statistics indicated that $\mathrm{BC}$ was the most common of all cancers in women, with 994 diagnoses in 2012 (37.3 percent) (Directorate of Information Studies and Research, 2005; Jordan Cancer Registry (JCR, 2012).

The growing prevalence of $\mathrm{BC}$ incriminates many factors in development of $\mathrm{BC}$ such as heredity, age, reproductive history, oral contraceptives, breast density, parity, breastfeeding, alcohol use, body mass index (BMI), exercise, hormone replacement therapy, and menstrual history (Khan et al., 2010; Abbad et al., 2018; Lilyquist et al., 2018). The interaction between inherited mutated genes and environmental factors is believed to play a crucial role in cancer development (Khan et al., 2010). Cancer-related deaths are due to modifiable factors such as smoking, alcohol consumption, low fruit and vegetable intake and a high fat-diet (Danaei et al., 2005; Khan et al., 2010; Kamińska et al., 2015; Al Qadire et al., 2018). In this context, it is estimated that $5-10 \%$ of all breast carcinomas are inherited. $B R C A 1$ and $B R C A 2$ genes are responsible for $3-8 \%$ of all BCs and for $15-20 \%$ of the inherited $B C$ (Pilato et al., 2011; Easton et al., 2015).

There are also other gene mutations besides BRCA that could increase the risk of $\mathrm{BC}$. Researchers have discovered, and are continuing to discover, other abnormal genes e.g. BRIP1, CDH1, PTEN, TP53, and the STK11 genes that are less common than BRCA1, $B R C A 2$, and $P A L B 2$ but also can raise $\mathrm{BC}$ risk in each population (Easton et al., 2015; Lincoln et al., 2015; Shiovitz and Korde, 2015; Daly et al., 2017; Abbad et al., 2018; Lilyquist et al., 2018; Momozawa et al., 2018). 
BARD1, BRCA1, BRCA2, PALB2, and RAD51D genes were associated with high risk for triple-negative $\mathrm{BC}$ and greater than 20 percent lifetime risk for overall $\mathrm{BC}$ among Caucasians (Shimelis et al., 2018). They observed a similar trend among African Americans population. Prediction models suggest that there are unlikely to be additional yet to be identified as high-penetrance genes.

The human X-box binding protein-1 (XBP1) gene is located on chromosome 22q12.1 (Liou et al., 1990). XBP1 is a major component of the unfolded protein response (UPR) and is essential for maintaining protein homeostasis and reducing cellular stresses (Hetz et al., 2013). Evidence has emerged that high expression of the nuclear $X B P 1$ gene plays a role in BC development (Bertucci et al., 2000; Ding et al., 2004; Scriven et al., 2009; Chen et al., 2014; Ming et al., 2015; Wang et al., 2017; McGrath et al., 2018).

Since almost all the available data are from the population of the European descendent (Lilyquist et al., 2018; Mavaddat et al, 2019), it is unclear whether clinical interpretations are generally applicable to other populations. The finding of Hoffman et al., (2019) highlighted the utility of performing additional searches for genetic variants for $\mathrm{BC}$ in non-European populations. In Jordan, $30.5 \%$ of the $\mathrm{BC}$ cases were diagnosed at stage III and IV, thus great efforts should be made to improve this percentage through a good surveillance system and screening programmes for high-risk groups. To date, $18 \%$ of the familial risk of $\mathrm{BC}$ can be explained by common single nucleotide polymorphisms (SNPs) (Lilyquist et al., 2018). Single nucleotide polymorphisms (SNPs) risk information can potentially improve the accuracy of BC risk prediction (Fung et al., 2019). The aim of this study was to evaluate the relationship between exon 1 and promoter $(-116 C / G)$ polymorphism (Figure 1) in the $X B P 1$ gene and $\mathrm{BC}$ risk in Jordanian women.

\section{Materials and Methods}

\section{Study population}

This study was conducted in a large hospital; King Abdullah University Hospital (North of Jordan). The sample consisted of two genetically unrelated groups: $60 \mathrm{BC}$ patients and 40 healthy; cancer free - control. The age of the two groups was matched ( $55 \pm 5$ years). None of the patients or healthy controls was cigarette smoker, alcohol or drug user. BC diagnosis was confirmed by standard laboratory and histopathology reports. Detailed information on histopathological variables and clinical data were available in a database. Approval to undertake this study was confirmed by the Ethics Committee of the King Abdullah University Hospital. All procedures were conducted according to the Declaration of Helsinki Principles. Written informed consent was obtained from each recruited subject.

\section{Sequence Analysis and SNP Genotyping}

Under complete aseptic conditions, $5 \mathrm{ml}$ of venous blood were collected from each participant in a sterile EDTA treated tube. DNA was extracted from peripheral blood samples using a Wizard Genomic DNA Purification Kit (Promega, USA) according to the manufacturer instructions. All the primers and restriction enzyme used in this study were designed manually. The location and fidelity of restriction enzyme and primers sequence were checked using the following software:

- http://primer3.ut.ee/,https://genome.ucsc.edu/,

- http://ensembl.org/Homo_sapiens/Gene, and

- http://www.labtools.us/nebcutter-v2-0/

The primers for rs2269577 SNP were 5'-GTTTCAGGACCGTGGCTATG-3' (Forward primer) and 5'-TCAGTCTGGAAAGCTCTCGG-3' (Reversed primer). We designed primers flanking the exon 1 , as well as $186 \mathrm{bp}$ upstream (containing putative regulatory elements) and $48 \mathrm{bp}$ from intron 1 sequences of XBP1 gene. Exon 1: 5'- GCGGAAAATGACCCCAAGTA-3' (Forward primer) and 5' - CCTAGTCCCGGCTTCAGATC-3' (Reversed primer). A total of $50 \mathrm{ng}$ genomic DNA was amplified in a $25 \mu \mathrm{L}$ final volume PCR reaction containing $0.4 \mu \mathrm{M}$ of each primer and $12.5 \mu \mathrm{L}$ of the SYBR Green PCR master mix $\left(\mathrm{GoTaq}^{\circledR} \mathrm{Green}\right.$ Master Mix, Promega, USA). Amplification was performed at $95^{\circ} \mathrm{C}$ for $5 \mathrm{~min}$ with an initial denaturation, followed by 35 cycles of $95^{\circ} \mathrm{C}$ for $30 \mathrm{Sec}, 52^{\circ} \mathrm{C}$ for $30 \mathrm{Sec}$, and $72^{\circ} \mathrm{C}$ for $30 \mathrm{Sec}$ and a final extension of $5 \mathrm{~min}$ at $72^{\circ} \mathrm{C}$. The amplified fragment of $190 \mathrm{bp}$ of PCR products were digested with the BstEII restriction enzyme.

The products were amplified by polymerase chain reactions (PCR) with touchdown program $\left(95^{\circ} \mathrm{C}\right.$ for 5 min; 30 cycles of $95^{\circ} \mathrm{C}$ for $30 \mathrm{~s}, 60^{\circ} \mathrm{C}$ for $30 \mathrm{~s}, 72^{\circ} \mathrm{C}$ for $30 \mathrm{~s}, 72^{\circ} \mathrm{C}$ for $5 \mathrm{~min}$ ).

\section{Statistical analysis}

The presence of Hardy-Weinberg equilibrium was examined by using the $X^{2}$ test for goodness of fit. Genotype and allele distributions between both groups were analyzed by the $X^{2}$ test for independence. Chi square test, odds ratio (OR) with 95\% confidence level (CI) estimation were performed in order to measure the association between $X B P 1$ polymorphisms and $\mathrm{BC}$ risk. The level of statistical significance was set at $\mathrm{P}<0.05$.

\section{Results}

As shown in Table 1, genotype distribution for the SNP $-116 \mathrm{C} \rightarrow \mathrm{G}$ was within the Hardy-Weinberg equilibrium in both groups $(\mathrm{P}=0.210)$. Table 2 presents the distribution of $X B P 1$ SNP $(-116 \mathrm{G} \rightarrow \mathrm{C})$ genotype and allele frequencies among $\mathrm{BC}$ patients and control subjects. There were no statistically significant associations between observed and expected numbers of $116 \mathrm{C} \rightarrow \mathrm{G}$ genotypes among $\mathrm{BC}$ patients and control. Results indicate that the highest genotypic frequency in patients and controls groups was $(61.7 \%$ versus $45 \%)$, respectively, while the lowest frequency $(10 \%)$ was recorded for the genotype (CC) in both groups. The OR and CI records for $\mathrm{GG}, \mathrm{GC}, \mathrm{CC}$ genotypes were $(0.73,0.18-2.91),(0.63,0.150-2.63)$ and (1.05, 0.91-5.20), respectively. The results show that the risk-associated $\mathrm{G}$ allele has nonsignificant difference than non-risk $\mathrm{C}$ allele; $75.8 \%$ versus $67.5 \%$ and $24.2 \%$ versus $32.5 \%$, in the patient and control groups, respectively with $\mathrm{OR}=0.662, \mathrm{CI}=.354-1.240$ and $\mathrm{P}>0.05$. Furthermore, sequencing analysis revealed no remarkable mutations in 
Table 1. Chi-squared Comparisons between Genotype Distributions of XBP1 -116C/G in the Breast Cancer Patients and Control Group

\begin{tabular}{lcccccc}
\hline & Genotype & Observed & Expected & Genotype & Observed & Expected \\
\hline \multirow{2}{*}{$(-116 \mathrm{C} \rightarrow \mathrm{G})$} & $\mathrm{GG}$ & 37 & 33 & $\mathrm{GG}$ & 18 & 22 \\
& $\mathrm{GC}$ & 17 & 21 & $\mathrm{GC}$ & 18 & 14 \\
& $\mathrm{CC}$ & 6 & 6 & $\mathrm{CC}$ & 4 & 6 \\
p-value & & & & 0.210 & & \\
\hline
\end{tabular}

Table 2. Distribution of XBP1 SNP* $(-116 \mathrm{G} \rightarrow \mathrm{C})$ Genotype and Allele Frequencies among Breast Cancer Patients and Control Subjects

\begin{tabular}{cccccc}
\hline XBP1* $(-116 \mathrm{G} \rightarrow \mathrm{C})$ Genotype & Breast Cancer Number $(\%)$ & Control Number $(\%)$ & $\mathrm{OR}^{*}$ & $95 \%$ CI* & $\mathrm{p}$-Value $<0.05$ \\
\hline $\mathrm{GG}$ & $37(61.7 \%)$ & $18(45 \%)$ & 0.73 & $0.18-2.91$ & 0.655 \\
$\mathrm{GC}$ & $17(28.3 \%)$ & $18(45 \%)$ & 0.63 & $0.15-2.63$ & 0.525 \\
$\mathrm{CC}$ & $6(10 \%)$ & $4(10 \%)$ & 1.05 & $0.91-5.20$ & 0.079 \\
Allele Frequencies & & & & & \\
$\mathrm{G}$ & $91(75.8 \%)$ & $54(67.5 \%)$ & & & \\
$\mathrm{C}$ & $29(24.2 \%)$ & $26(32.5 \%)$ & 0.6619 & $0.3534-1.2395$ & 0.197 \\
\hline
\end{tabular}

* SNP, Single nucleotide polymorphism; XBP1, X-box binding protein-1; OR, Odds ratio; CI, confidence interval

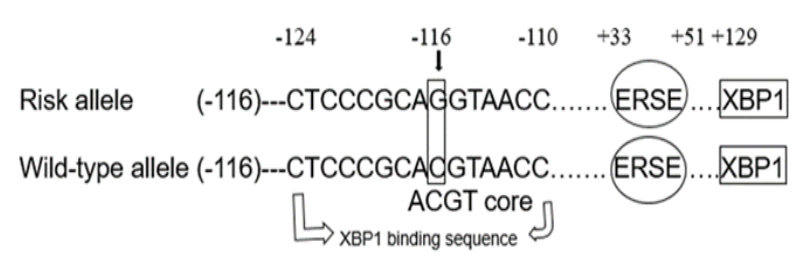

Figure 1. $-116 \mathrm{C} \rightarrow \mathrm{G}$ Polymorphism in $X B P 1$ Gene Promoter. $-116 \mathrm{C} \rightarrow \mathrm{G}$ Abolishes the ACGT Core Sequence. Numbers indicate the nucleotide position from the transcription site. ERSE, Endoplasmic reticulum stress response element.

exon 1 of the $X B P 1$ gene.

\section{Discussion}

The present study is the first report to examine the risk factors associated with $X B P 1 \mathrm{SNP}$ in BC progression in Jordan. Our statistical analysis demonstrated that the G/G genotype of the SNP rs 2269578 was not significantly associated $\mathrm{BC}$ compared with the homozygous $\mathrm{C} / \mathrm{C}$ genotype $(\mathrm{P}=0.073$, odds ratio $=0.662)$. This SNP is located in the promoter of the gene $X B P 1$, affecting the binding site of the gene. We were unable of detecting any remarkable mutation in exon 1 of $X B P 1$ gene. The power of this study was limited by small sample size. Therefore, the lack of association could be due to the small number of patients included in the analysis. This reflects the difficulty in enrolling untreated non-smoking patients which is necessary to avoid confounding effects that could influence the sensitive parameters being investigated in the study. SNP studies require thousands of cases and controls to have sufficient power to appreciate a change in risk, as individual alleles may be relatively common and even found in a majority of the population (Stratton and Rahman, 2008). There are no studies to suggest that that the use of single SNPs is informative for evaluating the risk of diseases, thus has quite small impact on clinical improvements in human health care outcomes (Medical
Policy Manual, 2019). Most of the BC susceptibility SNPs reside in intergenic or intronic regions of the genome and counter to early expectations, do not generally impact protein-coding regions (Edwards et al., 2013). Due to small number of investigated population we were unable of carrying out a subanalysis stratifying BC patients such as SNP association with stage of cancer, family history, overweight, hormone replacement therapy or radiotherapy.

Studies combining common variants together may provide some insight into individual risks of $\mathrm{BC}$. A number of SNPs associated with $\mathrm{BC}$ have been found at a high level of statistical significance and validated in two or more large, independent studies (Thomas et al., 2009; Ahmad et al., 2009, Kim et al., 2012). Stratification of women according to their risk of breast cancer based on polygenic risk scores could improve screening and prevention strategies (Mavaddat et al., 2019). Earlier studies using polygenic risk scores based on larger numbers of SNPs have successfully demonstrated an ability to stratify or individualize BC risk in a number of populations (Gail, 2008). A more recent OncoArray study suggested that all of the BC susceptibility markers to date explain up to $18 \%$ of familial relative risk (Michailidou et al., 2017). One way to identify SNP function and a potential target gene is to evaluate expression quantitative trait loci (eQTLs) to determine whether a SNP is impacting gene expression. It should be recalled that our study was not designed to evaluate the potential gene expression changes in relation to SNP. However, eQTL studies can be limited by the normal tissue that is available (Lonsdale et al., 2013). Transcriptome-wide association studies (TWAS) have been used to analyze both SNPs and gene expression to identify novel BC susceptibility genes and loci. By pairing genotyping data with gene expression data, SNPs that can predict gene expression can be selected (Lilyquist et al., 2018).

In conclusion, the clinical implication of our finding is that the $-116 C / G$ polymorphism of $X B P 1$ promoter 
may not be relevant to susceptibility to $\mathrm{BC}$ in Jordanian women. Moreover, analysis of exon1 of the XBP1 only does not negate the association with $\mathrm{BC}$, so this outcome cannot be generalized to other populations. The study provides important data to guide prospective genetic testing for BC susceptibility genes including the 22q12.1 locus in greater depth in an expanded sample size of BC cases and controls in other populations using improved methods.

\section{Acknowledgments}

We thank all the participants who took part in this research. This work was financially supported by the Deanship of Scientific Research and Graduate Studies at Yarmouk University under grant number (28/2015).

\section{References}

Abbad A, Baba H, Dehbi H, et al (2018). Genetics of breast cancer in African populations: A literature review. Glob Health Epidemiol Genom, 3, e8:1-12.

Ahmed S, Thomas G, Ghoussaini M, et al (2009). Newly discovered breast cancer susceptibility loci on 3p24 and 17q23.2. Nat Genet, 41, 585-90.

Al Qadire M, Alkhalaileh M, Hina H (2018). Risk factors for breast cancer among Jordanian women: A Case-control study. Iran J Public Health, 47, 49-56.

Arkoob K, Al-Nsour M, Al-Nemry O, Al-Hajawi B (2010). Epidemiology of breast cancer in women in Jordan: patient characteristics and survival analysis. East Mediterr Health J, 16, 1032-8

Bertucci F, Houlgatte R, Benziane A, et al 2000. Gene expression profiling of primary breast carcinomas using arrays of candidate genes. Hum Mol Genet, 9, 2981-91.

Chen X, Iliopoulos D, Zhang Q, et al (2014). XBP1 promotes triple-negative breast cancer by controlling the HIF $1 \alpha$ pathway. Nature, 508, 103-7.

Daly MB, Pilarski R, Berry M, et al (2017). NCCN guidelines insights: genetic/familial high-risk assessment: breast and ovarian, version 2.2017. J Natl Comp Cancer, 15, 9-20.

Danaei G, Vander Hoorn S, Lopez AD, Murray CJ, Ezzati M (2005). Causes of cancer in the world: comparative risk assessment of nine behavioral and environmental risk actors. Lancet, 366, 1784-93.

Ding LH, Ye QN, Yan JH, et al (2004). XBP-1 interacts with estrogen receptor alpha (ERalpha). Sheng Wu Gong Cheng Xиe Bao, 20, 332-6.

Directorate of Information Studies and Research. Mortality in Jordan (2008). Ministry of Health, Amman, Jordan.

Easton DF, Pharoah PDP, Antoniou AC, et al (2015). Gene-panel sequencing and the prediction of breast-cancer risk. NEngl JMed, 372, 2243-57.

Edwards SL, Beesley J, French JD, Dunning AM (2013). Beyond GWASs: Illuminating the dark road from association to function. Am J Hum Genet, 93, 779-97.

Fung SM, Wong XY, Lee SX, et al (2019). Performance of single nucleotide polymorphisms in breast cancer risk prediction models: A Systematic review and meta-analysis. Cancer Epidemiol Biomarkers Prev, 28, 506-21.

Gail MH (2008). Discriminatory accuracy from single-nucleotide polymorphisms in models to predict breast cancer risk. J Natl Cancer Inst, 100, 1037-41.

Hetz C, Chevet E, and Harding HP (2013). Targeting the unfolded protein response in disease. Nat Rev Drug Discov,
12, 703-19.

Hoffman J, Fejerman L, Donglei Hu D, et al (2019). Identification of novel common breast cancer risk variants at the 6q25 locus among Latinas. Breast Cancer Res, 21, 3.

Jordan Cancer Registry (2012). Cancer Incidence in Jordan. Ministry of Health, Hashemite Kingdom of Jordan.

Kamińska M, Ciszewski T, Łopacka-Szatan K, Miotła P, Starosławska E (2015). Breast cancer risk factors. Prz Menopauzalny, 14, 196-202.

Khan N, Afaq F, Mukhtar H (2010). Lifestyle as risk factor for cancer: Evidence from human studies. Cancer Lett, 293, 133-43.

Kim HC, Lee JY, Sung H, et al (2012). A genome-wide association study identifies a breast cancer risk variant in ERBB4 at 2q34: results from the Seoul Breast Cancer Study. Breast Cancer Res, 14, R56.

Lilyquist J, Ruddy KJ, Vachon CM, Couch FJ (2018). Common genetic variation and breast cancer risk - Past, present, and future. Cancer Epidemiol Biomarkers Prev, 27, 380-94.

Lincoln SE, Kobayashi Y, Anderson MJ, et al (2015). A Systematic comparison of traditional and multigene panel testing for hereditary breast and ovarian cancer genes in more than 1000 patients. J Mol Diagn, 17, 533-44.

Liou HC, Boothby MR, Finn PW, et al (1990). A new member of the leucine zipper class of proteins that binds to the HLA DR alpha promoter. Science, 247, 1581-4.

Lonsdale J, Thomas J, Salvatore M, et al (2013). The Genotype-tissue expression (GTEx) project. Nat Genet, 45, 580-5.

Mavaddat N, Michailidou K, Dennis J, et al (2019) Polygenic risk scores for prediction of breast cancer and breast cancer subtypes. Am J Hum Genet, 104, 21-34.

McGrath EP, Logue SE, Mnich K, et al (2018). The unfolded protein response in breast cancer. Cancers, 10, 344.

Medical Policy Manual (2019). Single-nucleotide variants (SNVs) to predict risk of nonfamilial breast cancer. Genetic Testing. Policy, pp 23.

Michailidou K, Lindstrom S, Dennis J, et al (2017). Association analysis identifies 65 new breast cancer risk loci. Nature, $551,92-4$.

Ming J, Ruan S, Wang M, et al (2015). A novel chemical, STF-083010, reverses tamoxifen-related drug resistance in breast cancer by inhibiting IRE1/XBP1. Oncotarget, 6, 40692-703.

Momozawa Y, Iwasaki Y, Parsons MT, et al (2015). Germline pathogenic variants of 11 breast cancer genes in 7,051 Japanese patients and 11,241 controls. Nat Commun, 2018, Article number: 4083.

Pilato B, Martinucci M, Danza K, et al (2011). Mutations and polymorphic BRCA variants transmission in breast cancer familial members. Breast Cancer Res Treat, 125, 651-7.

Scriven P, Coulson S, Haines R, et al (2009). Activation and clinical significance of the unfolded protein response in breast cancer. Br J Cancer, 101, 1692-8.

Shimelis H, LaDuca H, Hu C, et al (2018). Triple-negative breast cancer risk genes identified by multigene hereditary cancer panel testing. J Nat Cancer Inst, 110, 855-62.

Shiovitz S, Korde LA (2015). Genetics of breast cancer: a topic in evolution. Ann Oncol, 26, 1291-9.

Stratton MR, Rahman N (2008). The emerging landscape of breast cancer susceptibility. Nat Genet, 40, 17-22.

Thomas G, Jacobs KB, Kraft P, et al (2009). A multistage genome-wide association in breast cancer identifies two new risk alleles at $1 \mathrm{p} 11.2$ and $14 \mathrm{q} 24.1$ (RAD1L1). Nat Genet, 41, 579-84.

Wang M, Ruan S, Ming J, Dong F (2017). Nuclear expression of XBP1s is correlated with breast cancer survival: a 
retrospective analysis based on tissue microarray. Onco Targets Ther, 10, 5927-34.

World Health Organization (2008). International Agency International Agency for Research on Cancer. World Cancer Fact Sheet.

\section{(c) (i) (8)}

This work is licensed under a Creative Commons AttributionNon Commercial 4.0 International License. 